
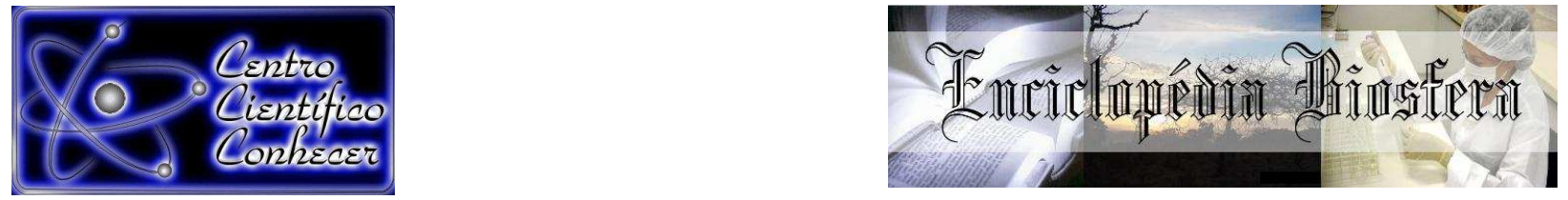

\title{
LEVANTAMENTO TÉCNICO DA PRODUÇÃO DE MANDIOCA NA REGIÃO DO TRIÂNGULO MINEIRO
}

\author{
Igor Souza Pereira ${ }^{1}$. Márcia Toyota Pereira ${ }^{2}$. Rodrigo Cassiano Rosalino ${ }^{3}$. Flávia de \\ Oliveira Borges Costa Neves ${ }^{3}$. Sidney Fernandes Bandeira ${ }^{4}$. \\ ${ }^{1}$ Professor Doutor do Departamento de Engenharia Agronômica do Instituto Federal \\ de Educação, Ciência e Tecnologia do Triângulo Mineiro, Uberlândia, MG, Brasil, \\ igor@iftm.edu.br. \\ ${ }^{2}$ Professora Doutora da Agronomia da Universidade Presidente Antônio Carlos, \\ Campus Uberlândia, Uberlândia, MG, Brasil. \\ ${ }^{3}$ Graduandos em Engenharia Agronômica, do Instituto Federal de Educação, Ciência \\ e Tecnologia do Triângulo Mineiro. \\ ${ }^{4}$ Professor Doutor do Departamento de Tecnologia em Alimentos do Instituto Federal \\ de Educação, Ciência e Tecnologia do Triângulo Mineiro, Uberlândia, MG, Brasil
}

Recebido em: 03/10/2016 - Aprovado em: 21/11/2016 - Publicado em: 05/12/2016 DOI: 10.18677/EnciBio 2016B 063

Nesse trabalho foram investigados aspectos socioeconômicos, fatores de produção e de comercialização da mandioca segundo produtores rurais do Triângulo Mineiro, Estado de Minas Gerais. O levantamento de dados envolveu a aplicação de questionários com 25 produtores rurais durante a 26a Semana da Família Rural do Instituto Federal do Triângulo Mineiro, Campus Uberlândia. Foram entrevistados agricultores de ambos os sexos com idade média de 42 anos caracterizados pela baixa escolaridade e na maioria proprietários da terra. Os agricultores preferem plantar variedades precoces de mandioca sendo constatado uma baixa diversidade de variedades, com predominância da Cacau, Amarela e Castelinho com o plantio ocorrendo predominantemente na época chuvosa, entre outubro a dezembro. Há uma baixa utilização de insumos em que $40 \%$ dos agricultores realizam a correção do solo e $48 \%$ realiza adubações. As plantas infestantes são manejadas por $80 \%$ dos agricultores. Dentre as pragas destacam-se as formigas cortadeiras, seguido dos cupins e do mandarová. As podridões radiculares seguido pelas doenças viróticas foram as doenças mais relatadas. A mandioca produzida em sua maioria para subsistência e com baixo acompanhamento técnico.

PALAVRAS-CHAVE: comercialização, Manihot esculenta, produção.

\section{TECHNICAL RESEARCH OF CASSAVA PRODUCTION IN THE TRIÂNGULO MINEIRO REGION}

\footnotetext{
ABSTRACT

The present study was investigated socioeconomic, production factors and commercialization's cassava second farmers of Triângulo Mineiro in Minas Gerais state. Data collection involved the use of questionnaires with 25 farmers during the 26th Rural Family Week in Triângulo Mineiro Federal Institute, Campus Uberlândia. ENCICLOPÉDIA BIOSFERA, Centro Científico Conhecer - Goiânia, v.13 n.24; p. 672 2016
} 
Men and women farmers were interviewed with an average age of 42 years characterized by low education and most landowners. Farmers prefer to plant early varieties of cassava and revealed a low diversity of varieties, especially Cacau, Amarela and Castelinho varieties with planting occurring in the rainy season predominantly, from October to December. There is a low use of inputs in which $40 \%$ of the farmers hold the soil correction and $48 \%$ held fertilizations. Weeds are managed by $80 \%$ of farmers. Among the pests there are the leafcutter ants, followed by termites and ello sphinx. The root rots followed by viral diseases were the most frequently reported diseases. Cassava produced mostly for subsistence and low technical support.

KEYWORDS: Manihot esculenta, production, commercialization.

\section{INTRODUÇÃO}

O Triângulo Mineiro e Alto Paranaíba (MG), destaca-se no cenário nacional por ser uma região com agricultura altamente tecnificada, especialmente na produção de soja, milho e cana-de-açúcar (SOUZA \& CLEPS JÚNIOR, 2009). Inserida predominantemente no bioma cerrado, com relevo plano a suave, o que facilita as operações agrícolas mecanizadas sendo considerada a mais dinâmica e desenvolvida do estado, possuindo grande potencial produtivo para grãos (BASTOS \& GOMES, 2011). Porém, essas culturas destacadas, especialmente a cultura da soja, são consideradas responsáveis pela substituição de lavouras alimentares como a mandioca, conforme foi detalhado por LEMOS (2015) no estado do Maranhão e pela cana-de-açúcar no Triângulo Mineiro segundo SOUZA \& CLEPS JÚNIOR (2009).

Particularmente em Campo Florido (MG), município pertencente a essa mesorregião, houve uma redução em torno de $86 \%$ no cultivo da mandioca no período de 1997 a 2007, resultado do arrendamento de grandes áreas pelas usinas sucroalcooleiras. $O$ fato mais preocupante refere-se ao arrendamento de propriedades rurais dentro de projetos de assentamentos do Incra (Instituto Nacional de Colonização e Reforma Agrária). Nesses projetos, houve a substituição de outras lavouras alimentares além da mandioca, como a abóbora e a pimenta (SOUZA \& CLEPS JÚNIOR, 2009).

A substituição da mandioca pela cultura da cana-de-açúcar pode levar a problemas sociais, pois a mandioca constitui-se numa das principais fontes de carboidratos disponíveis aos extratos sociais de baixa renda (ARRUDA, 1985). Tem importante participação na geração de emprego e de renda, especialmente para pequenos e médios produtores (MENDES et al., 2009) possuindo na região, um mercado consumidor demandante pelo produto, uma vez que a população urbana da mesorregião ultrapassa 2,1 milhões de habitantes segundo IBGE (2010). A cultura da mandioca é tradicionalmente cultivada no país, adaptando-se a diferentes condições edafoclimáticas (AGUIAR et al., 2011), sendo bastante versátil quanto ao seu uso (PEREIRA \& PEREIRA, 2015).

A mandioca pode ser produzida para duas finalidades, para indústria, em que se cultiva a mandioca para indústria e a mandioca de mesa, que é comercializada in natura e/ou minimamente processada (CARDOSO \& GAMEIRO, 2006; MEZETTE et al., 2009). Agronomicamente, a cultura requer práticas simples para seu cultivo que vão da escolha do local de plantio, correção e adubação do solo, a aquisição de variedades adaptadas (MEZETTE et al., 2009), preparo das manivas, plantio em época e condições adequadas, controle de plantas daninhas, pragas e doenças até 
a colheita na época adequada (MATTOS et al., 2006; FIALHO \& VIEIRA, 2011a). No entanto, a não adoção de tais práticas acarretam na manutenção de um baixo status produtivo, perpetuando práticas obsoletas de produção ou ainda abandono da atividade (CARVALHO et al., 2009).

Quanto ao sistema produtivo quando se leva em consideração as interconexões entre a origem da mão de obra, o nível tecnológico, a participação no mercado e o grau de intensidade do uso de capital na exploração, a mandiocultura, apresenta três tipologias básicas: a unidade doméstica, a unidade familiar e a unidade empresarial. A unidade doméstica caracteriza-se pelo uso de mão de obra familiar, baixo nível tecnológico da produção e de capital de exploração e pequena participação do mercado. Com médio nível tecnológico e de utilização do capital, a unidade familiar, tem uma participação significativa no mercado. A contratação de mão de obra de terceiros é a característica marcante da unidade empresarial, o nível tecnológico e de participação no mercado, assim como o grau de intensidade do uso de capital de exploração é semelhante às unidades do tipo familiar. Essa última unidade, com a do tipo empresarial, responde pela maior parte da produção de raízes nos estados do Centro-Sul (CARDOSO \& GAMEIRO, 2006).

Diante dessa perspectiva de produção de mandioca pela agricultura familiar e a necessidade de um levantamento de demandas para futuros projetos de pesquisa, são necessárias informações básicas acerca da cultura para a região do Triângulo Mineiro no Estado de Minas Gerais. Desse modo, este trabalho teve como objetivo identificar os fatores técnicos envolvidos no processo de produção de mandioca por agricultores familiares na região do Triângulo Mineiro.

\section{MATERIAL E MÉTODOS}

Foram selecionados para estudo produtores da mesorregião do Triângulo Mineiro e Alto Paranaíba, do Estado de Minas Gerais, Brasil, presentes na 26 Semana da Família Rural do Instituto Federal de Educação, Ciência e Tecnologia do Triângulo Mineiro Campus Uberlândia, no município de Uberlândia (MG). Este evento tem caráter anual sendo realizado pelo IFTM em parceria com a EMATERMG (Empresa de Assistência Técnica e Extensão Rural do Estado de Minas Gerais), com público proveniente do Triângulo Mineiro/Alto Paranaíba.

Para tanto, realizou-se uma pesquisa descritiva com amostragem de 25 produtores de mandioca, levantados aleatoriamente entre os 450 participantes, por meio de entrevistas individuais, durante o período evento, que ocorreu entre os dias 15 e 18 do mês de julho de 2014. A aplicação do questionário ocorreu somente para os participantes do evento que se apresentaram como produtores de mandioca. $O$ número de selecionados correspondeu à capacidade operacional de aplicação durante o tempo do evento e da disponibilidade e interesse do produtor em responder ao mesmo.

A abordagem levou em consideração temas quantitativos e qualitativos, por meio de perguntas estruturadas, dicotômicas e de múltipla escolha. As perguntas abertas e estruturadas versaram sobre perfil sócio educacional dos agricultores, da produção de mandioca e a finalidade da produção tais como: (1) idade, sexo e escolaridade do produtor; (2) tamanho do imóvel e forma de posse; (3) variedade (s) de mandioca cultivada (s); (4) época de plantio; (5) espaçamento utilizado; (6) adoção de práticas culturais para o manejo de plantas infestantes; (7) realização de calagem e adubação (8) ocorrência de pragas e doenças; (9) fatores de 
comercialização e (10) assistência técnica. Para análise dos dados utilizou-se estatística descritiva mediante análise de frequência simples.

\section{Perfil dos agricultores e ocupação da terra}

\section{RESULTADOS E DISCUSSÃO}

Constatou-se que $24,0 \%$ dos produtores são do sexo feminino e $76,0 \%$ do sexo masculino. Além disso, $48,0 \%$ dos entrevistados possuíam idade média superior a 50 anos, 24,0\% possuíam idade entre 37 e 49 anos, 16,0\% possuíam idade inferior a 25 anos e 8,0\% possuíam idade entre 26 e 36 anos (Tabela 1).

Em relação à escolaridade dos entrevistados, o ensino médio completo foi a escolaridade mais declarada, segundo $44,0 \%$ dos agricultores. $O$ ensino fundamental completo, ensino fundamental incompleto e superior incompleto foi declarado igualmente por $16,0 \%$ dos entrevistados. Somente $4,0 \%$ dos agricultores em questão possuíam ensino superior completo.

Este fato sugere que os produtores de mandioca, em relação à escolaridade, são bastante diversificados. Destaca-se a baixa frequência de produtores declarando possuir o ensino superior, porém a região é assistida por grande número de instituições públicas e particulares de ensino superior.

TABELA 1. Perfil dos agricultores e características técnicas das propriedades. Uberlândia (MG).

\begin{tabular}{cc}
\hline Sexo & Porcentagem observada (\%) \\
Feminino & 24 \\
Masculino & 76 \\
\hline Idade média (anos) & 16 \\
\hline $\mathbf{2 5}$ anos & 8 \\
$\mathbf{2 6}$-36 anos & 24 \\
$\mathbf{3 7 - 4 9}$ anos & 48 \\
$\mathbf{> 5 0}$ anos & \\
\hline Escolaridade & 16 \\
\hline Ensino fundamental incompleto & 16 \\
Ensino fundamental completo & 4 \\
Ensino médio incompleto & 44 \\
Ensino médio completo & 16 \\
Ensino superior incompleto & 4 \\
Ensino superior completo & \\
\hline Propriedade rural (tamanho em ha) & 40 \\
\hline$<10$ ha & 16 \\
10-20 ha & 44 \\
$>\mathbf{2 0}$ ha & 68 \\
\hline Proprietário & 4 \\
Arrendatário & 28 \\
\hline Cessão do Incra &
\end{tabular}

Fonte: Dados coletados na pesquisa e elaborados pelos autores.

Os entrevistados declararam-se envolvidos em atividades rurais sendo que $68,0 \%$ desses se declararam agricultores proprietários rurais, $28,0 \%$ se declararam 
agricultores que receberam terras por cessão do Incra e 4,0\% se declararam produtores rurais por arrendamento (Tabela 1).

A forma de ocupação da terra é uma característica importante, pois o agricultor que é regular junto ao INCRA (Instituto Nacional de Colonização e Reforma Agrária) viabiliza o acesso às diferentes políticas públicas como é o caso do financiamento rural com recursos do Pronaf (Programa Nacional de Fortalecimento da Agricultura Familiar) (BACEN-Banco Central do Brasil, 2015). Pode-se verificar nesse estudo que $44,0 \%$ dos entrevistados possuem sob sua posse áreas com tamanho superior a 20 ha, 40,0\% possuem propriedades com tamanho inferior a 10 ha e 16,0\% com tamanho de 10 a 20 ha.

\section{Caracterização dos sistemas de produção de mandioca}

Quanto ao ciclo variedades de mandioca plantadas, 84,0\% dos agricultores indicaram preferência pelas variedades precoces, $28,0 \%$ pelas semiprecoces e $8,0 \%$ pelas tardias, destaca-se que alguns agricultores indicaram preferência por mais de um tipo de variedade quanto ao ciclo cultural. A mandioca possui um ciclo que pode variar de 8 a 24 meses com variações na produtividade de raízes e na quantidade percentual de amido (TAKAHASHI e GONÇALO, 2005), dependendo da variedade e das condições edafoclimáticas da região de plantio (MATTOS et al., 2006). São consideradas variedades precoces aquelas que têm o ciclo entre 10 a 14 meses após o plantio, semiprecoces, têm o ciclo entre 14 a 16 meses e as tardias possuem o ciclo maior que 18 meses (MATTOS et al., 2006).

Em relação às variedades mais cultivadas pelos agricultores foram relatadas as variedades chamadas Cacau, seguida por Amarela, Castelinho, Vassourinha, Pão Doce, Paulistinha, IAC12 e Roxa entre outras (Figura 1).

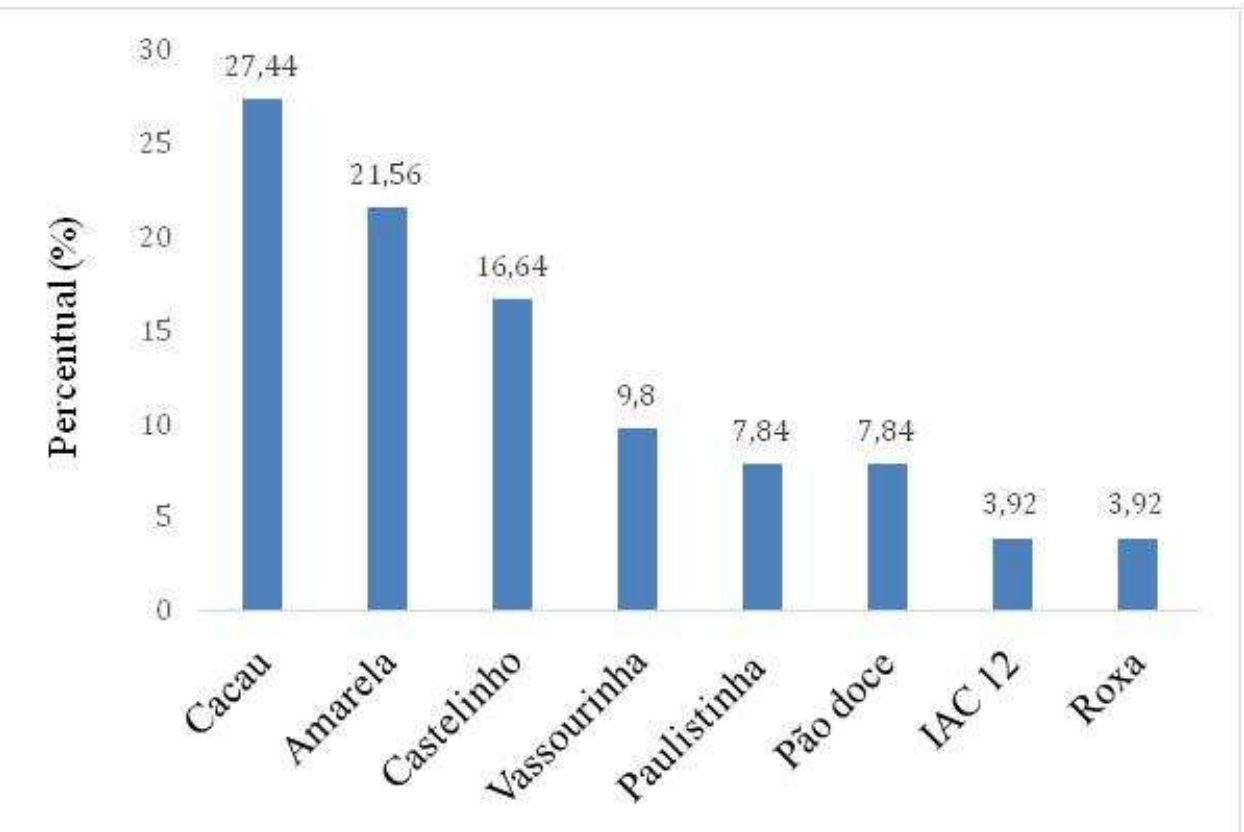

FIGURA 1. Percentual das variedades utilizadas pelos produtores de mandioca.

Fonte: Dados coletados na pesquisa e elaborados pelos autores. 
Segundo FUKUDA (2000), há mais de 4100 variedades de mandioca catalogadas no Brasil, sobretudo na região nordeste do país. Pelo baixo número de variedades indicadas sugere-se uma provável perda de recursos genéticos dessa espécie na região ou mesmo a repetição de nomes para variedades diferentes. Em outro estudo realizado por CARVALHO et al. (2009), somente na região sudoeste da Bahia foram levantados mais de 160 variedades de mandioca, com a predominância de 10 variedades. RAMOS et al. (2011) observaram em duas comunidades de Cáceres (MT), 14 variedades diferentes, porém sem comprovação genética conforme explicitado pelos autores.

Sugere-se que sejam feitas pesquisas in situ para a coleta de manivas das variedades existentes e posterior classificação com o intuito de se levantar a real diversidade genética dessa espécie na região utilizando-se os descritos morfológicos descritos por FUKUDA \& GUEVARA (1998).

Quanto à época para plantio, 72,0\% dos produtores disseram plantar nos meses de outubro a dezembro; $24,0 \%$ disseram plantar nos meses de janeiro a março e $4,0 \%$ entre os meses de abril a junho e julho ao setembro, para ambos períodos respectivamente.

A época de plantio está correlacionada com a época de chuva da mesorregião em estudo (ALVARES et al., 2013). No Triângulo Mineiro e Alto Paranaíba, as maiores médias pluviométricas ocorrem justamente no período de maior frequência de plantio, sendo que nos meses de abril a setembro há elevado déficit hídrico (ALVARES et al., 2013), restringindo a produção de mandioca sem a utilização da irrigação. A umidade e o calor são elementos essenciais para a brotação e o enraizamento de estacas, acarretando num bom estabelecimento da lavoura de mandioca (MATTOS et al., 2006).

Em relação à consorciação da mandioca com outras culturas, 64\% dos entrevistados declararam não plantar a mandioca em consórcio com outras culturas enquanto que $36 \%$ declarou consorciar a mandioca com uma ou mais culturas. Daqueles que realizam o consórcio, 33\% realizam com o milho (Zea mays), 33\% consorciam com o amendoim (Arachis hypogea) e outros 22\% com feijão comum (Phaseolus vulgaris). Outras culturas foram citadas nesse consórcio tais como, a abóbora (Cucurbita pepo), a melancia (Citrullus lunatus) ou na entrelinha dos citrus (Citrus spp.) e banana (Musa spp.).

A condição de baixa diversificação apresentada expõe os agricultores locais ao risco de perdas produtivas na produção da cultura principal. Essas perdas resultam de problemas fitossanitários, climáticos ou mesmo aqueles relacionados à venda da produção. Essa condição é comum em produtores mandioca em diferentes regiões do país, como no Estado do Pará (SANTOS \& SANTANA, 2012). Quanto à calagem, prática relacionada à correção da acidez do solo pela incorporação de corretivos, $60 \%$ dos entrevistados não realizam nenhuma forma de correção do solo ao passo que o restante realiza.

A calagem é considerada uma prática essencial para o cultivo em solos do cerrado, devido às características químicas naturais do mesmo, considerados ácidos e de baixa fertilidade natural. A não realização dessa prática expõe as plantas a teores elevados de $\mathrm{pH}$ e do $\mathrm{Al}^{3+}$ tóxico que acarretam, entre outros problemas, num baixo aproveitamento dos nutrientes disponíveis no solo ou dos provenientes de adubações. Os problemas advindos da não realização da calagem são observados na cultura da mandioca, sendo essa considerada uma cultura tolerante à acidez (LOPES et al., 1990). 
Quando se questionou sobre a adubação das lavouras, foi possível constatar que $52 \%$ dos agricultores entrevistados não realizam nenhum tipo de adubação e $48 \%$ as realizam. Dentre os que realizam algum tipo de adubação, $41,7 \%$ aplicam somente adubos orgânicos, especialmente o esterco bovino curtido. Para 16,6\% dos entrevistados, a adubação química é aplicada exclusivamente e para outros $41,7 \%$ a adubação ocorre de ambas as formas, ou seja, utilizando-se de fontes orgânicas e fontes químicas.

E importante destacar que a cultura da mandioca é reconhecidamente extratora de nutrientes, sendo necessária a reposição dos macronutrientes e micronutrientes para a manutenção do status produtivo. A adubação orgânica é importante não somente pela reposição de nutrientes como o condicionamento do solo, melhorando a aeração e retenção da água (FIALHO \& VIEIRA, 2011b).

Em relação às práticas de manejo das plantas infestantes, $80 \%$ dos agricultores adotam alguma prática. Para $85 \%$ dos que adotam, a forma mais comum foi do tipo mecânico por meio de práticas de eliminação dessas plantas, como capina com enxada, roçagem e cultivo mecanizado. Os outros $15 \%$ dizem adotar um manejo integrado, utilizando tanto o manejo do tipo mecânico quanto o controle químico com a utilização de herbicidas.

A manutenção das lavouras de mandioca livres da matocompetição é recomendada até os 90 a 120 dias após o plantio das manivas (MOURA, 2000; FIALHO \& VIEIRA, 2011c). A não adoção de práticas de manejo das plantas infestantes pode acarretar numa redução na produtividade e qualidade das raízes colhidas, além de elevar o custo da colheita.

Quando questionados sobre as pragas mais relevantes, $76 \%$ dos agricultores relataram as formigas cortadeiras (Atta sp.), seguido pelos cupins e mandarová (Erinnyis ello), para $28 \%$ e $4 \%$ respectivamente. 12\% declararam não observar pragas nas áreas de plantio ou considerar irrelevantes. A ocorrência dessas pragas é comum na cultura, demandando táticas específicas para o seu controle, sobretudo das formigas do gênero Atta (CARVALHO et al., 2009; OLIVEIRA \& PAULAMORAES, 2011).

Quando questionados sobre as enfermidades fúngicas, viróticas ou bacterianas, para $64 \%$ dos entrevistados não há ocorrência ou são imperceptíveis para os mesmos, enquanto $24 \%$ relataram as podridões radiculares e os outros $12 \%$ relataram as viroses em geral como enfermidades de ocorrência comum. A podridão radicular é uma importante doença para a cultura, sobretudo quando a lavoura não é colhida na época adequada ou é plantada em locais com excesso de umidade (ANJOS et al., 2011). Causada por diferentes agentes fúngicos, a doença pode ser controlada pelo uso do manejo integrado pela adoção de variedades resistentes, o plantio em áreas bem drenadas e sem histórico da doença, destruição dos restos culturais e adoção da rotação de cultura entre outras (ANJOS et al., 2011).

\section{Finalidade da produção e assistência técnica}

Questionados sobre a finalidade da produção de mandioca, obteve-se que $80 \%$ dos produtores entrevistados produziam mandioca para o consumo próprio enquanto que $20 \%$ dos produtores produziam mandioca para comercialização, que ocorre em mercados, feira livres, no Ceasa, nas próprias casas e também pelo PNAE (Programa Nacional de Alimentação Escolar).

Segundo CARVALHO (2005), a mandiocultura pode ser uma cultura melhor explorada pelos beneficiários de lotes em assentamentos do INCRA na região, 
podendo substituir culturas, como o milho e o feijão, consideradas mais vulneráveis às oscilações de preços e exigentes agronomicamente quanto à fertilidade do solo e tratos culturais. No entanto, existe a ilusão, de que a cultura da mandioca é rústica ao ponto de não exigir a correção do solo. Tal fato, leva à degradação e redução da fertilidade do solo, piorando a situação econômica desse agricultor.

Tradicionalmente a mandioca é comercializada in natura em feiras livres (PEREIRA \& PEREIRA, 2015), sacolões e em grandes redes de supermercados. Na mesorregião do Triângulo Mineiro, o mercado consumidor ultrapassa 2,1 milhões de habitantes segundo IBGE (2010). Nas cidades polo de Uberlândia e Uberaba, a mandioca é comercializada na forma minimamente processada ou congelada, existindo várias marcas que são encontradas nas grandes redes de supermercados ou mesmo sacolões, sendo essa mais uma oportunidade de comercialização da cultura.

Sob o ponto de vista econômico, a produção e comercialização de mandioca é vantajosa para os agricultores familiares, sobretudo para aqueles que encontramse próximos aos centros consumidores pelo seu baixo tempo de prateleira (SANTOS \& MITJA, 2012). As raízes após colhida mantêm-se íntegras ente 48 e 72 dependendo da variedade. Após esse tempo iniciam processo de degradação classificadas como sendo fisiológica e microbiológica (HENRIQUE et al., 2010).

Quando questionados sobre a assistência técnica, 72\% dos entrevistados declararam não serem assistidos nas suas propriedades enquanto que $28 \%$ é assistido, mesmo que esporadicamente. Para os que são assistidos, $85,71 \%$ é assistido pelos técnicos da EMATER-MG (Empresa de Assistência Técnica e Extensão Rural do Estado de Minas Gerais) ou segundo 14,28\%, por técnicos autônomos.

A EMATER-MG ocupa papel fundamental da difusão de tecnologia para os agricultores familiares no Estado de Minas Gerais, papel esse destacado nessa pesquisa. Ademais, a EMATER-MG é instituição co-promotora do evento em que essa pesquisa foi realizada e, portanto parte dos agricultores presentes são diretamente atendidos pela empresa. Destaca-se o elevado número de agricultores não assistidos, muito provavelmente pelo papel de subsistência dessa planta conforme relatado anteriormente.

Sugere-se a partir desse trabalho a realização de treinamentos com objetivo de se obter melhor eficiência no controle das formigas e outros problemas fitossanitários. Ações devem ser implementadas para o desenvolvimento do sistema produtivo da cultura na região como meio de fortalecer a agricultura familiar.

\section{CONCLUSÃO}

A produção de mandioca na mesorregião predomina em pequenas propriedades, com até 10 ha, sendo cultivada para subsistência ou comercialização nas cidades, com preferência para as variedades precoces. Foi constatada baixa diversidade de variedades utilizadas pelos agricultores, com o plantio ocorrendo predominantemente na época chuvosa, entre outubro a dezembro. Há uma baixa utilização de insumos em que $40 \%$ dos agricultores realizam a correção do solo e $48 \%$ realiza adubações. As plantas infestantes são manejadas por $80 \%$ dos agricultores. Dentre as pragas destacam-se as formigas cortadeiras, seguido dos cupins e do mandarová. As podridões radiculares seguido pelas doenças viróticas foram as doenças mais relatadas. A mandioca produzida em sua maioria para subsistência e com baixo acompanhamento técnico. 


\section{AGRADECIMENTOS}

Ao Conselho Nacional de Desenvolvimento Científico e Tecnológico (CNPq) e Ministério do Desenvolvimento Agrário (MDA) pelo financiamento às pesquisas do grupo de pesquisa (CNPq/MDA Proc. 576869/2008-2).

Aos entrevistados e entrevistadores que participaram do trabalho.

\section{REFERÊNCIAS}

ANDRÉ, T.B.; SANTOS, A. C. Uso de produtos da cultura da mandioca (Manihot) na produção animal. Enciclopédia Biosfera, Centro Científico Conhecer: Goiânia GO, v.8, n.15, p.1622-1647, $2012 . \quad$ Disponível em:<http://www.conhecer.org.br/enciclop/2012b/ciencias\%20agrarias/uso\%20de\%20 produtos.pdf>. Acesso em 16 set. 16.

ANJOS, J.R.N.; SILVA, M.S.; VIEIRA, E.A.; FIALHO, J.F. Principais doenças da mandioca no Cerrado. In. FIALHO, J.F.; VIEIRA, E.A. (eds.): Mandioca no Cerrado: orientações técnicas. Embrapa Cerrados: Planaltina, DF, p.117-135, 2011. b. ISBN: 978-85-7075-058-7. Disponível em: <http://www.fbb.org.br/data/files/8AE389DB3309CEE001331C7AC60B55C6/manual mandioca_no_cerrado.pdf>. Acesso em 25 de set. 2016.

BACEN - Banco Central do Brasil. FAQ - Programa Nacional de Fortalecimento da Agricultura Familiar - Pronaf. 2015. Disponível em:< https://www.bcb.gov.br/pre/bc_atende/port/PRONAF.asp>. Acesso em 25 set. 2016.

CARDOSO, C.E.L.; GAMEIRO, A.H. Caracterização da cadeia agroindustrial. In: SOUZA, L.D.; FARIAS, A.R.N.; MATTOS, P.L.P.; FUKUDA, W.M.G. Aspectos Socioeconômicos e Agronômicos da Mandioca. Embrapa Mandioca e Fruticultura Tropical: Cruz das Almas-BA, 2006. p.19-40.

CARVALHO, D. D. Diagnóstico rural participativo (DRP) das condições sócioculturais dos assentamentos de reforma agrária na região do Triângulo Mineiro-MG. In: Simpósio de Reforma Agrária: Balanço Crítico e Perspectivas. Programa de Apoio Científico e Tecnológico em Assentamentos de Reforma Agrária (PACTo/TM): Uberlândia-MG, $2005 . \quad$ Disponível em: $<$ http://www.simposioreformaagraria.propp.ufu.br/trabalhos/>. Acesso em 16 set. 2016.

CARVALHO, F.M; VIANA, A.E.S.; CARDOSO, C.E.L.; MATSUMOTO, S.N.; GOMES, I.R. Sistemas de produção de mandioca em treze municípios da Região Sudoeste da Bahia. Bragantia, IAC:Campinas-SP, v.68, n. 3. 2009. Disponível em: <http://dx.doi.org/10.1590/S0006-87052009000300017>. Acesso em 16 set. 2016.

FIALHO, J.F.; VIEIRA, E.A. (eds.) . Mandioca no Cerrado: orientações técnicas. Embrapa Cerrados: Planaltina, DF, 208p. 2011. a. ISBN: 978-85-7075-058-7. Disponível em: <http://www.fbb.org.br/data/files/8AE389DB3309CEE001331C7AC60B55C6/manual _mandioca_no_cerrado.pdf>. Acesso em 25 de set. 2016. 
FIALHO, J.F.; VIEIRA, E.A. Manejo do solo no cultivo da mandioca. In. FIALHO, J.F.; VIEIRA, E.A. (eds.): Mandioca no Cerrado: orientações técnicas. Embrapa Cerrados: Planaltina, DF, p.37-57, 2011. b. ISBN: 978-85-7075-058-7. Disponível em:

<http://www.fbb.org.br/data/files/8AE389DB3309CEE001331C7AC60B55C6/manual _mandioca_no_cerrado.pdf>. Acesso em 25 de set. 2016.

FIALHO, J.F.; VIEIRA, E.A. Manejo e tratos culturais da mandioca. In. FIALHO, J.F.; VIEIRA, E.A. (eds.): Mandioca no Cerrado: orientações técnicas. Embrapa Cerrados: Planaltina, DF, p.59-90, 2011. c. ISBN: 978-85-7075-058-7. Disponível em: <http://www.fbb.org.br/data/files/8AE389DB3309CEE001331C7AC60B55C6/ manual_mandioca_no_cerrado.pdf>. Acesso em 25 de set. 2016.

FUKUDA, W.M.G.; GUEVARA, C.L. Descritores morfológicos e agronômicos para a caracterização da mandioca (Manihot esculenta Crantz). Documentos 78, CNPMF: Cruz das Almas (BA), 32p. 1998. Disponível em:< https://www.infoteca.cnptia.embrapa.br/bitstream/doc/955031/1/Descritoresmorfologi cosWaniaFukudaDocumentos781998.pdf.>. Acesso em 26 set. 16.

HENRIQUE, C.M; PRATI, P.; SARMENTO, S.B.S. Alterações fisiológicas em raízes de mandioca minimamente processadas. Pesquisa e Tecnologia, APTA: Campinas - SP, v.7, n.1, 2010. Disponível em:< http://www.aptaregional.sp.gov.br/acesse-osartigos-pesquisa-e-tecnologia/edicao-2010/2010-janeiro-junho/754-alteracoesfisiologicas-em-raizes-de-mandioca-minimamente-processadas/file.html>. Acesso em 16 set. 2016.

IBGE - Instituto Brasileiro de Geografia e Estatística. Censo Demográfico do IBGE ano 2010. Disponível em: < http://www.ibge.gov.br/home/estatistica/populacao/censo2010/caracteristicas_da_po pulacao/caracteristicas_da_populacao_tab_municipios_zip_xls.shtm>. Acesso em 29 de setembro de 2016.

LEMOS, J.J.S. Efeitos da expansão da soja na resiliência da agricultura familiar no Maranhão. Revista de Política Agrícola, MAPA:Brasília - DF, v. 24, n. 2, p. 26-37, Abr./Maio/Jun, $2015 . \quad$ Disponível em: $<$ https://seer.sede.embrapa.br/index.php/RPA/article/view/1012>. Acesso em 22 set. 2016.

LOPES, A.S.; SILVA, M.C.; GUILHERME, L.R.G. Acidez do solo e calagem. Boletim técnico no 1. ANDA - Associação Nacional para Difusão de Adubos: São Paulo-SP. 22p. 1990. Disponível em:< http://www.anda.org.br/multimidia/boletim_01.pdf>. Acesso em: 25 set. 16.

MATTOS, P.L.P. de; FARIAS, A.R.N.; FERREIRA, J.R. (Eds.). Mandioca: o produtor pergunta, a Embrapa responde. Embrapa Informação Tecnológica: Brasília - DF, 2006. 176 p. Disponível em: <https://goo.gl/fxoHRs>. Acesso em: 16 set. 2016. 
MEZETTE, T.F.; CARVALHO C.R.L.; FELTRAN, J.C.; GALERA, J.M.S.V; VALLE, T.L. Produtividade e tempo de cocção de clones de mandioca de mesa em processo de seleção. Revista Raízes e Amidos Tropicais, CERAT-UNESP: Botucatu - SP, v. 3, 2009. Disponível em: < http://dx.doi.org/10.17766/1808-981X.2007v3n1p537$540>$. Acesso em 16 set. 16 .

MOURA G. M. Interferência de plantas daninhas na cultura da mandioca (Manihot esculenta Crantz) no estado do Acre. Planta Daninha, Viçosa-MG, v. 18, n. 3, p. 451-456, 2000. Disponível em:< http://dx.doi.org/10.1590/S010083582000000300009 >. Acesso em 25 de set. 2016.

OLIVEIRA, C.M.; PAULA-MORAES, S.V. Principais pragas da mandioca no Cerrado. In.: FIALHO, J.F.; VIEIRA, E.A. (eds.). Mandioca no Cerrado: orientações técnicas. Embrapa Cerrados: Planaltina, DF, p. 93-114. 2011. ISBN: 978-85-7075058-7. Disponível em: <http://www.fbb.org.br/data/files/ 8AE389DB3309CEE001331C7AC60B55C6/manual_mandioca_no_cerrado.pdf>. Acesso em 25 de set. 2016.

PEREIRA, I.S.; PEREIRA, M.T. Caracterização do mercado consumidor de mandioca de mesa in natura em Conceição Do Araguaia (Pará). Enciclopédia Biosfera, Centro Científico Conhecer: Goiânia (GO), v.11, n.21, p. 2410-2417, 2015. Disponível em:< https://goo.gl/3Vxlom>. Acesso em:16 set. 2016.

RAMOS, F.T.; SEABRA JR., S.; BARELLI, M.A.A.; RAMOS, D.T. Sistemas de produção de mandioca em comunidades locais de Cáceres-MT: um estudo de caso. Revista de Ciências Agro-Ambientais, Alta Floresta-MT, v.9, n.2, p.211-224, 2011. Disponível em:< http:/www.unemat.br/revistas/rcaa/docs/vol92/ARTIGO_4_RCAA_v9n2a2011.pdf>. Acesso em 26 set. 2016.

SANTOS, A. M. dos; MITJA, D.. Agricultura familiar e desenvolvimento local: os desafios para a sustentabilidade econômico-ecológica na comunidade de Palmares II, Parauapebas, PA. Interações, Univ. Católica Dom Bosco: Campo Grande-MS [online]. v.13, n.1, p.39-48, 2012. ISSN 1518-7012. Disponível em:<http://dx.doi.org/10.1590/S1518-70122012000100004>. Acesso em 16 set. 16.

SANTOS, M.A.S.; SANTANA, A.C. Caracterização socioeconômica da produção e comercialização de farinha de mandioca no município de Portel, Arquipélago do Marajó, Estado do Pará. Revista Verde de Agroecologia e Desenvolvimento Sustentável, UFRN:Mossoró - RN, v. 7, n. 5, p. 73-86, 2012 (Edição Especial). ISSN 1981-8203 Disponível em: < http://www.gvaa.com.br/revista/index.php/RVADS/article/view/1755/1462>. Acesso em 16 set. 2016.

SOUZA, A. G.; CLEPS JUNIOR, J. Expansão da cana-de-açúcar no Triângulo Mineiro e os efeitos sobre a agricultura familiar e o trabalho rural. Revista Tópos, FCT-Unesp: Presidente Prudente - SP v. 3, n. 2, p.8-35, 2009. Disponível em:< http://revista.fct.unesp.br/index.php/topos/article/viewFile/2235/2046>. Acesso em 16 set. 2016. 
TAKAHASHI, M.; GONÇALO, S. A cultura da mandioca. Paranavaí: Olímpica, 2005. 116p. 